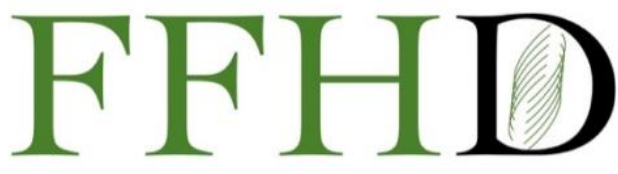

Functional Foods in Health and Disease

\title{
Anti-salmonella potential and antioxidant activity of fermented fruit-based juice by lactic acid bacteria and its biotransformation
}

\author{
Wanida Laosee ${ }^{1}$, Duangporn Kantachote ${ }^{2}$, Worrapanit Chansuwan ${ }^{3}$, Chakree Thongraung ${ }^{3}$, Nualpun Sirinupong ${ }^{3 *}$ \\ ${ }^{1}$ Functional Food and Nutrition Program, Faculty of Agro-Industry, Prince of Songkla University, Hat Yai, Songkhla, \\ Thailand. 2Department of Microbiology, Faculty of Science, Prince of Songkla University, Hat Yai, Songkhla, Thailand. \\ ${ }^{3}$ Center of Excellence in Functional Foods and Gastronomy, Prince of Songkla University, Hat Yai, Songkhla, Thailand
}

${ }^{*}$ Corresponding author: Nualpun Sirinupong, Ph.D. Center of Excellence in Functional Foods and Gastronomy, Prince of Songkla University, Hat Yai, Songkhla, Thailand.

Submission Date: June 18 ${ }^{\text {th }}, 2021$; Acceptance Date: August 4 ${ }^{\text {th }}, 2021$; Publication Date: August 23rd 2021

Please cite this as: Laosee W., Kantachote D., Chansuwan W., Thongraung C., Sirinupong N. Anti-salmonella potential and antioxidant activity of fermented fruit-based juice by lactic acid bacteria and its biotransformation. Functional Foods in Health and Disease 2021. 11(8): 368-384. DOI: https://www.doi.org/10.31989/ffhd.v11i8.813

\section{ABSTRACT}

Background: Lactic acid bacteria-based fermentation clearly contributes to improving nutritional value and exhibits various health benefits. The demand for non-dairy functional beverages, such as fruit beverages, as an alternative vehicle for probiotics is increasing because of lifestyle choices or health conditions. Therefore, the objective of this study was to evaluate the anti-Salmonella potential and antioxidant activity of fermented fruitbased juice by lactic acid bacteria and its biotransformation.

Methods: In this study, to produce the fermented fruit-based juice (FFJ), the mixed fruit juice (MFJ) was fermented by Lactobacillus plantarum and Lactobacillus salivarius for $72 \mathrm{hrs}$. The potential function, antiSalmonella by the minimum inhibitory concentration (MIC), minimum bactericidal concentration (MBC), and antibiofilm activities of FFJ against Salmonella Typhi DMST 22842 was evaluated. The antioxidative capacity was determined by DPPH and FRAP assay. The active volatile compounds were identified by GC-MS.

Results: A novel functional FFJ showed excellent growth capacity with 8 log CFU/mL of probiotics Lactobacillus plantarum and Lactobacillus salivarius. MIC and MBC values in the FFJ were $500 \mathrm{mg} / \mathrm{mL}$ after $72 \mathrm{hrs}$ of fermentation. After $48 \mathrm{hrs}$ of fermentation, biofilm formation inhibition was significant $(p<0.05)$ with $95.27 \% \pm$ $2.26 \%$ inhibition; biofilm metabolic activity inhibition was also significant $(p<0.05)$ with $89.25 \% \pm 0.18 \%$ 
inhibition. The volatile compounds present in the FFJ were fruity flavors and aromas, most of have antimicrobial and antioxidant properties. These compounds comprise various classes, including alcohols, organic acid, ester, and ketone. In both LAB fermentations, the most abundant volatile alcohol was isoamyl alcohol, followed by 1hexanol and 2,3-Butanolone; acetic acid was only present in L. plantarum fermentation. In addition, DPPH radical scavenging and FRAP assay showed the mixed fruit juice had dramatically increased antioxidant activity after 48 hrs of fermentation.

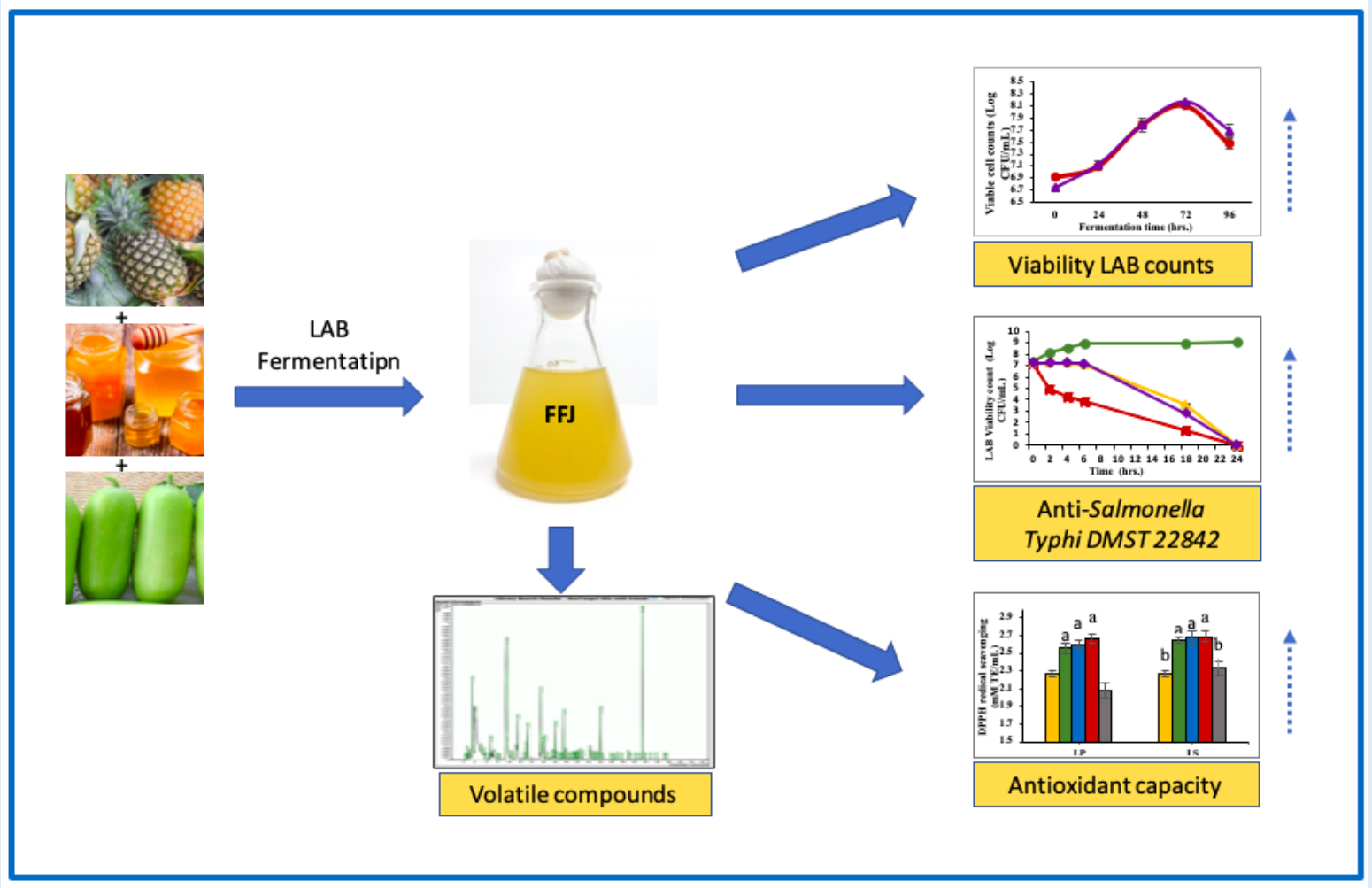

Conclusion: The findings of this work indicate that the obtained fermented fruit-based juice (FFJ) showed excellent growth capacity of probiotics, Lactobacillus plantarum and Lactobacillus salivarius, and produced the volatile compounds from biotransformation. This not only improved fruit flavor and aroma, but also influenced antibacterial activity against the pathogen Salmonella Typhi DMST 22842, as well as increased antioxidant activity. Therefore, the FFJ could be a novel functional fermented drink for vegan and non-diary consumption.

Keywords: Lactic acid bacteria, Probiotics, Biotransformation, Non-dairy functional beverage, Anti-Salmonella.

CFFC 2021. This is an Open Access article distributed under the terms of the Creative Commons Attribution 4.0 License (http://creativecommons.org/licenses/by/4.0)

\section{INTRODUCTION}

Consumer concern and increasing knowledge of the impacts of food on health has led to the demand for food products with functional properties, as well as the consumption of functional beverages. Nowadays, drink consumers demand nutritive and healthy beverages, with pleasant flavor, low-caloric intake, and non-dairy options. The consumption of 
fermented products increased worldwide along with the concomitant reduction in dairy consumption [1]. The demand for non-dairy functional beverages, such as fruit beverages, as an alternative vehicle for probiotics is increasing because of lifestyle choices or health conditions [2]. Fruits contain many bioactive compounds, including health promoting phytochemicals [3], such as antioxidants [4]. The nutritional and functional properties of fruits have been widely studied. Pineapple (Ananas comosus L. Merr.) and winter melon (Benincasa hispida Cogn) were previously evaluated as potential antioxidant food sources and they were determined to contain phytochemicals (flavonoids, phenolic acids), vitamin C, minerals, free amino acids and phytosterol [5]. Honey, a natural sweetener, and the product of Apis mellifera honeybees, has been a favorite foodstuff since ancient times [6]. It is often considered as the 'natural healer' due to its composition and biological properties.

In present days, lactic acid bacteria (LAB)-based fermentation has a clear contribution in improving nutritional value and enhances health benefits, including aiding digestibility of various foods, decreasing lactose intolerance, controlling potential infections, and adding further functional bioactivity [7]. It is possible that the microbial biotransformation of fruit matrices occurs because most plant-based materials contain important nutrients, including sugars for microbial growth and other phytochemicals. Accordingly, the biotransformation of biologically active compounds in fruit and vegetable juices through $L A B$ fermentation is an active area of research. Fruit-based materials may be ideal media for cultivating beneficial bacteria, such as probiotics $L A B$, which concurrently enhances their nutritional functionality. Thus, various bioactive metabolites with health-promoting attributes could be obtained by biotransformation processes [8]. Moreover, due to their complex enzymes, functional benefits of lactic acid bacteria could also lead to the novel modification of flavor attributes.

Foodborne diseases remain a major public health concern worldwide and are mainly caused by the consumption of food contaminated with pathogenic organisms, including bacteria. However, foodborne pathogens can also cause various infectious illnesses in the human host, mostly associated with vomiting or diarrhea [9]. Salmonella enterica serovar Typhi is the most common foodborne pathogen implicated in foodborne disease [10]. Salmonella Typhi is a gram-negative enteropathogenic bacterium that can infect humans and cause a severe systemic infection called typhoid fever, due to its characteristic pathogenicity [11]. After entering a host, $S$. Typhi passes through the acidic stomach and duodenum, then invades the small intestine mucosa and survives in macrophages and monocytes. During this process, $S$. Typhi utilizes various strategies to overcome environmental stress through regulating gene expression, including increasing motility and biofilm formation [12]. Therefore, this study aimed to investigate Lactobacillus salivarius and Lactobacillus plantarum fermented in mixed fruit juice and their antiSalmonella potential, antioxidant activity, as well as any volatile compound production caused by their biotransformation. The findings will inform specific function and benefits targeting humans and tropical fruits application by LAB fermentation-based biotransformation. 


\section{MATERIALS AND METHODS}

Materials: Pineapple (Ananas comosus L.Merr.) and winter melon (Benincasa hispida Cogn.) were purchased from the local market in southern Thailand. Longan (Dimocarpus longan Lour.) honey was directly purchased from beekeepers and stored at $4^{\circ} \mathrm{C}$ before use. Honey was used in the experiment for the first 6 months.

Preparation of Lactic acid bacteria strains and inoculum: Lactobacillus salivarius and Lactobacillus plantarum were obtained in lyophilized from and were reactivated by culturing in $10 \mathrm{~mL}$ of de Man Rogosa and Sharpe (MRS) broth at $37^{\circ} \mathrm{C}$ for $24 \mathrm{hrs}$. The resulting $\mathrm{LAB}$ suspensions were then used as inoculum for $100 \mathrm{~mL}$ of MRS broth and incubated at $37^{\circ} \mathrm{C}$ for $24 \mathrm{hrs}$. The cell was harvested by centrifugation at $6000 \times \mathrm{g}$ at $4^{\circ} \mathrm{C}$ for $10 \mathrm{~min}$ and washed twice with sterile water. Then optical density (OD) at $660 \mathrm{~nm}$ was measured and appropriate dilutions were made in sterile water to obtain an OD of 2.5 to achieve LAB cells of approximately $1 \times 10^{8}$ $\mathrm{CFU} / \mathrm{mL}$. The LAB suspension was used as inoculum in the fermentation process.

Fermentation of mixed fruit juice: The mixed fruit juice consisted of an appropriated ratio of honey, winter melon and pineapple juices. The $\mathrm{pH}$ value was adjusted using food-grade $\mathrm{Na}_{2} \mathrm{CO}_{3}$. The resulting MFJ was pasteurized at $70^{\circ} \mathrm{C}$ for $10 \mathrm{~min}$ before fermentation. The $L A B$ suspension inoculum of approximately $1 \times 10^{8} \mathrm{CFU} / \mathrm{mL}$ was added into 1000 $\mathrm{mL}$ Erlenmeyer flasks containing $900 \mathrm{~mL}$ of sterile MFJ and incubated at $37^{\circ} \mathrm{C}$ for $96 \mathrm{hrs}$. The sterile mixed fruit juice with no inoculation was treated under the same condition and was used as control. The samples were taken every $24 \mathrm{hrs}$ to ensure a viable LAB count. Then the fermented fruit-based juice (FFJ) samples were centrifuged at $12000 \times \mathrm{g}$ at $4^{\circ} \mathrm{C}$ for $10 \mathrm{~min}$ to obtain supernatants for physiochemical, biological activity and volatile compound analysis as described below.

Determination of viable $L A B$ counts: Viable $L A B$ counts in the FFJ were obtained by serially diluting with $0.85 \% \mathrm{NaCl}$ solution to $10^{-4}-10^{-6}$ dilution, then using the spread plate method. Each dilution consisted of $100 \mu \mathrm{L}$ aliquots in triplicate and spread on plates containing MRS agar. The plates were incubated at $37^{\circ} \mathrm{C}$ for $48 \mathrm{hrs}$ and the plates containing 30-300 colonies were counted and recorded as log $\mathrm{CFU} / \mathrm{mL}$.

Determination of total titratable acidity and reducing sugar: Total titratable acidity (TTA) expressed as percentage of lactic acid was determined by dissolving the sample in distilled water and titrating it. Reducing sugar (RS) content was analyzed as glucose equivalents with Dinitrosalicylic acid (DNS) reagent. The DNS method used was as described by Miller [13], with some modifications. Absorbance was measured by UVSpectrophotometer and the curve was plotted to compare the reducing sugar content in the sample $(\mathrm{mg} / \mathrm{mL})$ against the glucose standard curve.

Preparation of Salmonella Typhi DMST 22842 culture: Salmonella Typhi DMST 22842 were cultured in Brain Heart Infusion (BHI) broth at $37^{\circ} \mathrm{C}$ for $24 \mathrm{hrs}$. After that, $O D$ at $600 \mathrm{~nm}$ was measured and appropriate dilutions were made in $\mathrm{BHI}$ broth to obtain an $\mathrm{OD}_{600}$ of 0.1 (approximately $1 \times 10^{8}$ 
$\mathrm{CFU} / \mathrm{mL}$ ). The obtained bacterial culture was used for anti-Salmonella analysis.

Determination of MIC and MBC: The anti-Salmonella activity was determined by finding the minimum inhibitory concentration (MIC) of the FFJ. MIC was measured using the serial broth dilution method, as outlined in the Clinical and Laboratory Standard Institute (CLSI) procedures [14]. Two-fold serial dilution of FFJ with $\mathrm{BHI}$ was prepared in a sterilized 96-well plate. The FFJ dilution was mixed with $100 \mu \mathrm{L}$ bacterial cultures, resulting in approximately $1 \times 10^{8}$ $\mathrm{CFU} / \mathrm{mL}$ and varied ranges of $15-1000 \mathrm{mg} / \mathrm{mL}$. Gentamicin concentration of $0.01-2.5 \mathrm{mg} / \mathrm{mL}$ was used as positive control. The plates were incubated at $37^{\circ} \mathrm{C}$ for $24 \mathrm{hrs}$. The MIC was defined as the lowest concentration of metabolites that inhibit the bacterial growth. To find the minimum bactericidal concentration (MBC), a $10 \mu \mathrm{L}$ aliquot of bacterial suspensions from the wells with no bacterial growth of a previous MIC test was added into a $\mathrm{BHI}$ agar and incubated at $37^{\circ} \mathrm{C}$ for $24 \mathrm{hrs}$. The MBC was defined as the lowest concentration that enables no growth of bacteria on agar (99.9\% kill).

Time-kill kinetics assay: Time-kill kinetics were performed to evaluate the killing dynamics to assess the antimicrobial effect of FFJ on Salmonella Typhi DMST 22842. A bacterial suspension of approximately $1 \times 10^{8} \mathrm{CFU} / \mathrm{mL}$ in $\mathrm{BHI}$ broth was used in assay. $5 \mathrm{~mL}$ of bacterial cultures were exposed to FFJ and Gentamicin at MIC value and incubated at $37^{\circ} \mathrm{C}$. A tube containing $5 \mathrm{~mL}$ of bacterial cultures without samples was used as a growth control. $100 \mu \mathrm{L}$ of each sample was taken at 0, 2, 4, 6, 18 and $24 \mathrm{hrs}$ and made into 10 -fold serial dilutions. Then $100 \mu \mathrm{L}$ aliquots obtained from each tube were inoculated on $\mathrm{BHI}$ agar plates for colony counts. The number of viable colonies was counted only from the plates containing 30-300 colonies and recorded as log $\mathrm{CFU} / \mathrm{mL}[15]$.

Biofilm biomass quantification: Biofilm formation assay by the method described by [16] was followed with some modifications. A $100 \mu \mathrm{L}$ of each FFJ at MIC value was added to each well of a sterilized 96-well plate. The $100 \mu \mathrm{L}$ gentamicin at MIC value was used as a negative control and $100 \mu \mathrm{L}$ distilled water was used as a positive control. Then, $100 \mu \mathrm{L}$ bacterial cultures (approximately $10^{8} \mathrm{CFU} / \mathrm{mL}$ ) were added into the well to obtain a final volume of $200 \mu \mathrm{L}$. The plate was incubated at $37^{\circ} \mathrm{C}$ for $24 \mathrm{hrs}$. The supernatant was removed, and the biofilm was washed with distilled water. The plate was fixed at $60^{\circ} \mathrm{C}$ for $1 \mathrm{hr}$ and the biofilm was stained with $0.1 \%$ solution of crystal violet in water. After staining, samples were washed twice with distilled water. Biofilm quantification was evaluated by adding $200 \mu \mathrm{L}$ of $30 \%$ acetic acid to obtain the biofilm formation. The absorbance was measured at $595 \mathrm{~nm}$ using a microplate reader.

Biofilm metabolic activity determination: The metabolic activity of biofilm was determined using the 3- $[4, \quad 5$-dimethylthiazol-2-yl]-2, 5diphenyltetrazolium bromide (MTT) reduction assay of [17] with some modifications. An aliquot of $200 \mu \mathrm{L}$ bacterial cultures (approximately $1 \times 10^{8} \mathrm{CFU} / \mathrm{mL}$ ) was inoculated in a sterilized 96 -well plate at $37^{\circ} \mathrm{C}$ for 24 hrs. After incubation, bacterial cultures were removed, and the microplates were dried. Then, 200 $\mu \mathrm{L}$ of the FFJ were added into each well. After incubation at $37^{\circ} \mathrm{C}$ for $24 \mathrm{hrs}$, wells were washed with 
$200 \mu \mathrm{L}$ of PBS. Then, $200 \mu \mathrm{L}$ of $0.25 \mathrm{mg} / \mathrm{mL} \mathrm{MTT}$ solution was added into each well and incubated at $37^{\circ} \mathrm{C}$ for $3 \mathrm{hrs}$. The solution was then removed, and the insoluble purple formazan generated by the bacterial enzymatic hydrolysis of MTT was dissolved in $2 \%$ DMSO. Finally, the absorbance was measured at $570 \mathrm{~nm}$ by the microplate reader. Gentamicin at MIC value was included as a negative control. The FFJ's percentage of biofilm inhibition was then compared with the positive control (distilled water).

Determination of antioxidant activity: The 2,2diphenyl-1-picrylhydrazyl (DPPH) radical scavenging activity in FFJ was evaluated using the method previously described with some modification [18]. The $200 \mu \mathrm{L}$ of sample solution was mixed with 1800 $\mu \mathrm{L}$ of $200 \mu \mathrm{M}$ methanolic DPPH solution. The mixture was incubated for $30 \mathrm{~min}$ at room temperature in the dark. The supernatant absorbance was measured with a spectrophotometer at $517 \mathrm{~nm}$. The ability of DPPH was expressed as millimolar of Trolox equivalent per milliliter of the sample.

The FRAP was performed according to the previously reported method [19] with slight modifications. The reaction mixture was prepared by mixing $100 \mathrm{~mL}$ of $0.3 \mathrm{M} \mathrm{pH} 3.6$ acetate buffer, $10 \mathrm{~mL}$ of $40 \mathrm{mM} \mathrm{2,4,6-Tri(2-pyridyl)-1,3,5-triazine} \mathrm{solution,}$ prepared with $40 \mathrm{mM} \mathrm{HCl}$ and $10 \mathrm{~mL}$ of $20 \mathrm{mM}$ $\mathrm{FeCl}_{3 .} 6 \mathrm{H}_{2} \mathrm{O}$. Then, $200 \mu \mathrm{L}$ of the sample solution was mixed with $1800 \mu \mathrm{L}$ of the reaction mixture and incubated at room temperature for $30 \mathrm{~min}$. The absorbance was measured at $593 \mathrm{~nm}$. Data was reported in millimolar of Trolox equivalent per milliliter of the sample.

Characterization of volatile compounds: Volatile compounds produced by biotransformation in the FFJ were characterized by the HS-SPME/GC-MS technique following the protocol reported by [20] with slight modification. The $2 \mathrm{~mL}$ of FFJ was added into a $20 \mathrm{~mL}$ glass vial. Head space micro-extraction was placed at $40^{\circ} \mathrm{C}$ for $30 \mathrm{~min}$. After $15 \mathrm{~min}$ of equilibration time, each analysis utilized a SPME fiber coated with $50 / 30 \mu \mathrm{m}$ of Divinylbenzene-CarboxenPolydimethylsiloxane (DVB/Carboxan/PDMS). Before each analysis, the fiber was conditioned by insertion into the GC-MS injector at $230^{\circ} \mathrm{C}$ for $2 \mathrm{~min}$; volatiles were desorbed by exposing the fiber into the GC injector for $2 \mathrm{~min}$ at $230^{\circ} \mathrm{C}$. The separation was performed on a VF-WASms capillary column (30 $\mathrm{m} \times$ $0.25 \mathrm{~mm} \times 0.25 \mu \mathrm{m}$ ) at programmed a temperature, starting from $50^{\circ} \mathrm{C}$ for $3 \mathrm{~min}$, increasing $5^{\circ} \mathrm{C}$ after each minute until reaching $200^{\circ} \mathrm{C}$, then maintaining this final temperature for $12 \mathrm{~min}$. The transfer line temperature was $250^{\circ} \mathrm{C}$. The signal acquisition mode was full scan (from $41 \mathrm{~m} / \mathrm{z}$ to $500 \mathrm{~m} / \mathrm{z}$ ). The volatile compounds produced by LAB in FFJ were identified based on their mass spectra compared with the $90 \%$ match factor of library (NIST 14) mass by spectra. Furthermore, to obtain a more confident identification. The linear retention indices (LRIs) were calculated on the retention time with a solution of C8C20 analysis under the same conditions applied for sample analyses.

Statistical analysis: All experiments were repeated in triplicate, and data was analyzed using the SPSS 21 software. All data are expressed as the mean values \pm standard deviation (SD). Analysis of variance (ANOVA) based on the control group was carried out to determine any significant differences $(p<0.05)$.

\section{RESULTS AND DISCUSSION}


Lactic acid bacteria viability: Viable LAB counts changed in FFJ during fermentation at $37^{\circ} \mathrm{C}$ for $96 \mathrm{hrs}$ with L. salivarius (LS) and L. plantarum (LP), as shown in Figure. 1. Both LAB strains showed a similar growth profile within $24 \mathrm{hrs}$ and reached maximum values after $72 \mathrm{hrs}$ of fermentation. The LS and LP showed maximum viable counts of $8.17 \pm 0.01 \log \mathrm{CFU} / \mathrm{mL}$ and $8.11 \pm 0.02 \log \mathrm{CFU} / \mathrm{mL}$, respectively. An obvious decrease in the microbial population was observed with LS and LP after $72 \mathrm{hrs}$ of fermentation. Since an acidic environment is created during LAB fermentation, nutrient differences potentially induced stress on the growth of LAB strains [21]. Overall, cell viability is the key factor to designing functional drink and our results indicated that the FFJ was able to sustain a viable level of LAB up to $72 \mathrm{hrs}$. This fermentation time could be used in further studies to develop functional drinks with health benefits from $L A B$ fermentation.

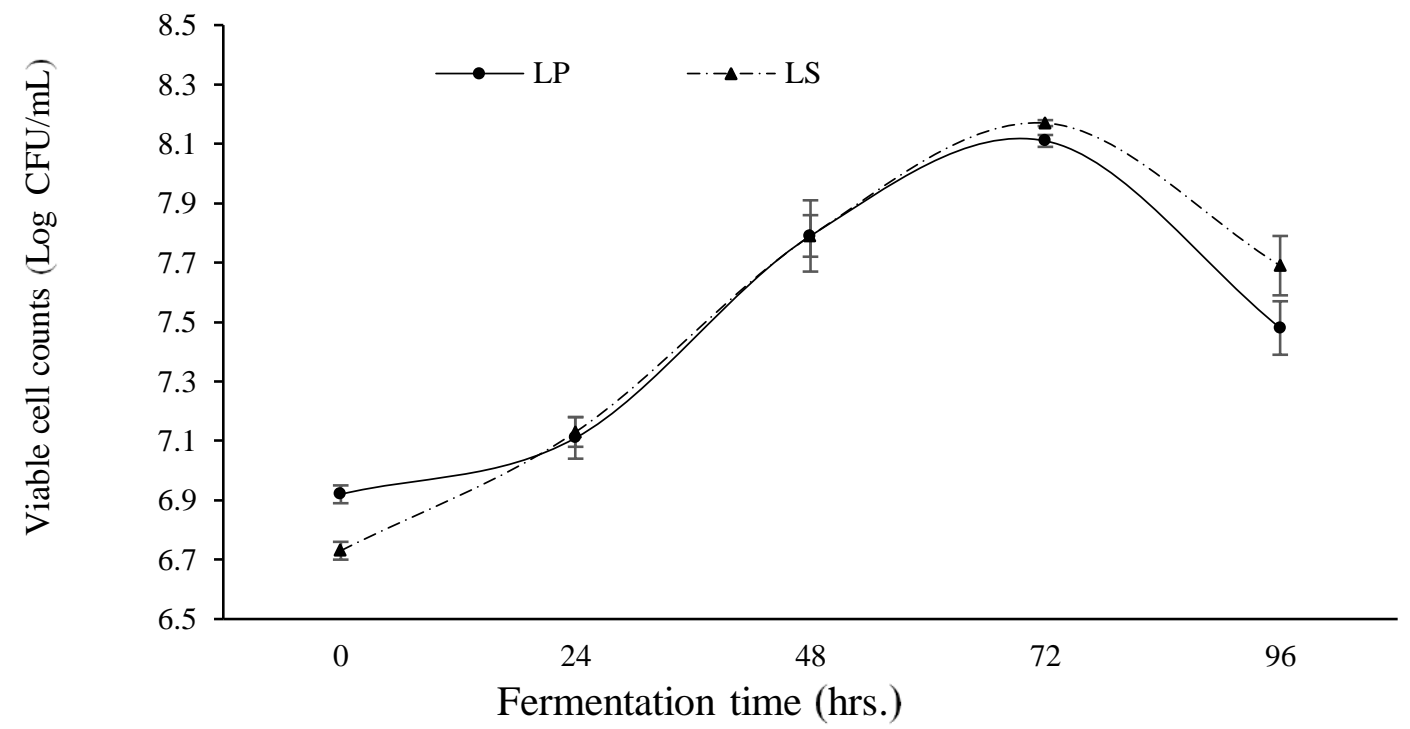

Figure 1. Viable cell counts of LAB during fermentation of fermented fruit-based juice. LP was represented $L$. plantarum and LS represented L. salivarius. Error bars indicate the standard deviation from three independent samples.

Reducing sugar and total titratable acidity: Sugar content in the fermented fruit-based juice (FFJ) has usually been assessed in terms of reducing sugar (RS). Profile changes in RS contents in FFJ are shown in Figure. 2. During the fermentation period from beginning to optimum at $72 \mathrm{hrs}$, the values of RS decreased then stayed relatively unchanged from 72 hrs to 96 hrs in both L. salivarius (LS) and L. Plantarum (LP). The decrease of RS in FFJ with L. salivarius was greater than that by L. Plantarum, indicating that FFJ with L. salivarius consumed sugar at a much faster rate than L. Plantarum, which is concordant to the growth profiles of both LAB. The decrease in sugar concentrations during fermentation was largely due to not only bioconversion into lactic acid, but also the utilization for growth and metabolism of LAB [22]. The profile of total titratable acidity (TTA) rapidly increased throughout the fermentation period, as shown in Figure 2. For both L. salivarius (LS) and $L$. plantarum (LP) FFJs, TTA initially rapidly increased and reached its highest at $72 \mathrm{hrs}$. Overall, the curve showed that L. salivarius produced significantly 
higher \%TTA than L. plantarum. The \%TTA of FFJ with LS increased from $0.33 \pm 0.04 \%$ to $1.15 \pm 0.07 \%$, whereas the \%TTA of FFJ with LP increased from 0.33 $\pm 0.04 \%$ to $1.05 \pm 0.01 \%$. Total titratable acidity increased because of acid production from sugar conversion during fermentation [23]. The greater amounts of TTA in FFJ with L. salivarius is potentially due to its homo-fermentative nature. This group of LAB efficiently metabolizes carbohydrates generating ATP, which is subsequently used for the biosynthesis of lactic acid. Meanwhile, L. Plantarum, which is facultatively hetero-fermentative, not only produces lactic acid, but also acetic acid and ethanol as main products [24].

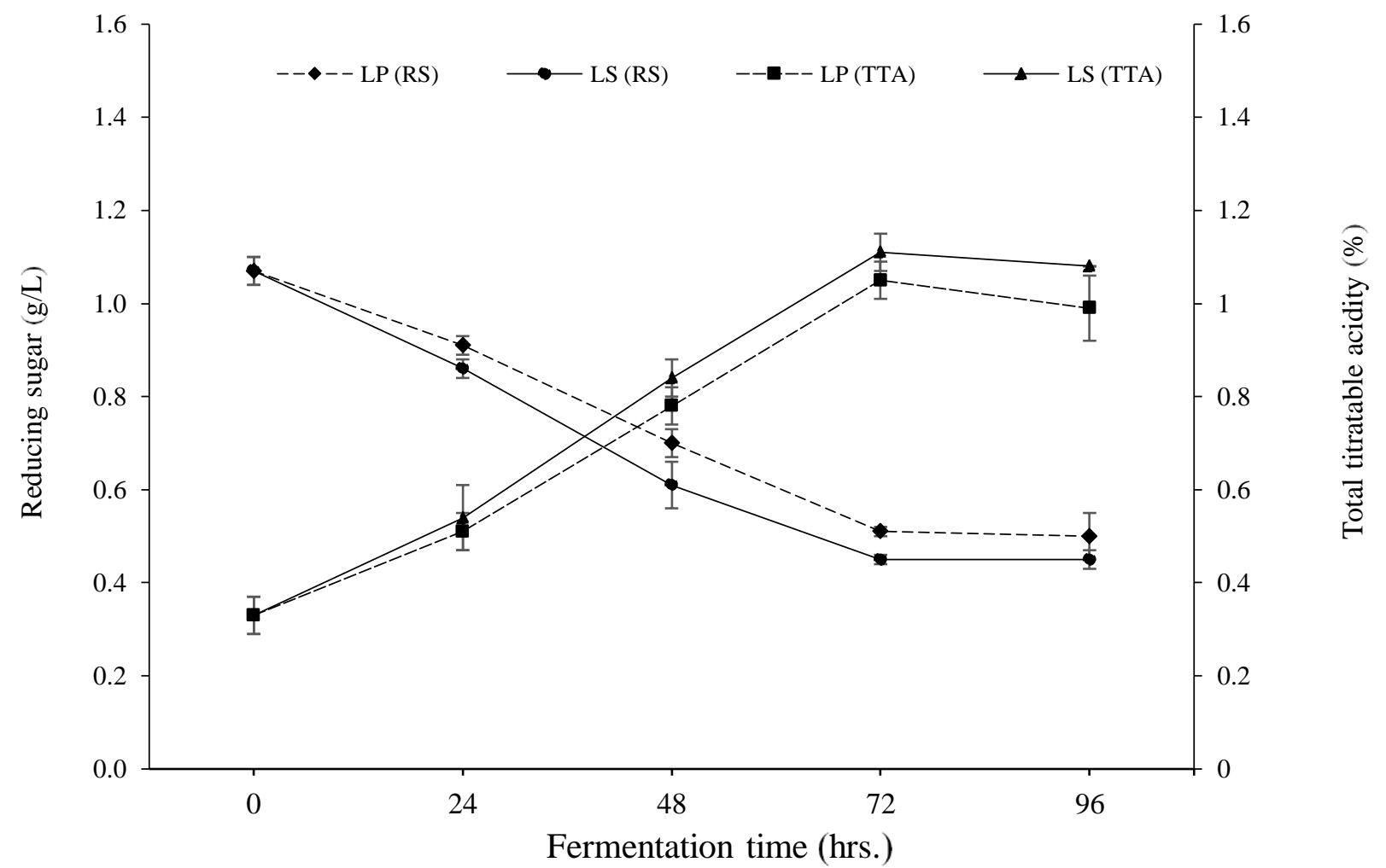

Figure 2. Changes in total titratable acidity and reducing sugar during FFJ. Error bars indicate the standard deviation from three independent samples.

MIC and MBC: The anti-Salmonella activity against Salmonella Typhi DMST 22842 of fermented fruitbased juice (FFJ) was assessed using their minimum inhibitory concentration (MIC) and bactericidal concentration $(\mathrm{MBC})$ values, as shown in Table 1. Gentamicin was used as positive control. The results showed that the non-fermented mixed fruit juice did not inhibit growth of Salmonella Typhi. Interestingly, the respective FFJs with L. plantarum and L. salivarius from 48to 96 hrs fermentation all inhibitedgrowth Salmonella Typhi with a MIC value of $500 \mathrm{mg} / \mathrm{mL}$; the MBC values were also $500 \mathrm{mg} / \mathrm{mL}$ but only occurred at $72 \mathrm{hrs}$. Gentamicin had MIC values of $0.039 \mathrm{mg} / \mathrm{mL}$ and $\mathrm{MBC}$ values of $0.078 \mathrm{mg} / \mathrm{mL}$. These antiSalmonella effects could be due to the antimicrobial substances produced by LAB during fermentation. LAB typically produce anti-Salmonella compounds against foodborne pathogens, including bacteriocin 
peptides, organic acids, free fatty acids, ammonia, diacetyl, hydrogen peroxide and enzymes [25]. Lactic acid is also known to function as a permeabilizer in
Gram-negative bacteria and their outer membranes, allowing other compounds to perform synergistically with lactic acid [26].

Table 1 Minimum inhibitory concentration (MIC) and Minimum Bactericidal concentration (MBC) values of fermented fruit-based juice by L. plantarum (FFJ LP) and L. salivarius (FFJ LS) against Salmonella Typhi DMST 22842.

\begin{tabular}{|l|c|c|}
\hline \multicolumn{1}{|c|}{ Treatments } & Concentration $(\mathrm{mg} / \mathrm{mL})$ \\
\hline Gentamicin & MIC & MBC \\
\hline MFJ & 0.039 & 0.078 \\
\hline FFJ LP & - & - \\
\hline $\mathbf{2 4}$ hrs. & & \\
\hline $\mathbf{4 8}$ hrs. & - & - \\
\hline $\mathbf{7 2}$ hrs. & 500 & - \\
\hline $\mathbf{9 6}$ hrs. & 500 & 500 \\
\hline FFJ LS & 500 & 500 \\
\hline $\mathbf{2 4}$ hrs. & & \\
\hline $\mathbf{4 8}$ hrs. & - & - \\
\hline $\mathbf{7 2}$ hrs. & 500 & - \\
\hline $\mathbf{9 6}$ hrs. & 500 & 500 \\
\hline
\end{tabular}

- No MIC and MBC value was observed due to lack of anti-Salmonella effect.

Biofilm biomass and biofilm methbolic activity inhibition: Inhibition of biofilm formation was conducted in fermented fruit-based juice, which showed at least $90 \%$ reduction (at MIC value concentration) in cell attachment of tested Salmonella Typhi DMST 22842 by crytal violet assay. The results showed different effects on the growth and development of a preformed biofilm, as presented in Table 2. The inhibition percentages of biofilm formation obtained for the $S$. Typhi strains was significant $(p<0.05)$ reaching $90.62 \pm 0.46 \%$ to $95.27 \pm 2.26 \%$. Biofilm metabolic activity inhibition was observed on the preformed biofilms. Fermented fruit-based juices were tested against $24 \mathrm{hr}$ preformed biofilms using 3-(4,5-dimethylthiazol-2yl)-2,5-diphenyltetrazolium bromide (tetrazolium dye MTT) to stain metabolic active adhered bacteria. As presented in Table 2, the strongest metabolic activity inhibitions observed against the Salmonella Typhi biofilm ranged from $88.74 \pm 0.27 \%$ to $89.00 \pm 0.24 \%$ . The results reveal that FFJ with $L$. plantarum and FFJ with L. salivarius at both $48 \mathrm{hrs}$ and $72 \mathrm{hrs}$ inhibit biofilm formation and biofilm methbolic activity of Salmonella Typhi DMST 22842. 
Table 2 Biofilm formation and biofilm metabolic activity inhibition of fermented fruit-based juice (FFJ) by $L$. plantarum (LP) and L. salivarius (LS) at $48 \mathrm{hrs}$ and $72 \mathrm{hrs}$ fermentation against preformed biofilms by Salmonella Typhi DMST 22842.

\begin{tabular}{|l|c|c|}
\hline \multicolumn{2}{|c|}{ FFJ / Control } & \multicolumn{2}{|c|}{$\begin{array}{c}\text { Salmonella Typhi } \\
\text { formation (\%) }\end{array}$} & Biofilm metabolic activity (\%) \\
\hline Gentamicin $\mathbf{( 0 . 0 3 9} \mathbf{~} \mathbf{~ g} / \mathbf{m l})$ & $92.98 \pm 2.09^{\mathrm{ab}}$ & $85.19 \pm 1.08^{\mathrm{c}}$ \\
\hline LP48 & $95.27 \pm 2.26^{\mathrm{a}}$ & $89.00 \pm 0.24^{\mathrm{ab}}$ \\
\hline LP72 & $93.72 \pm 1.05^{\mathrm{ab}}$ & $88.17 \pm 0.09^{\mathrm{b}}$ \\
\hline LS48 & $92.84 \pm 2.19^{\mathrm{ab}}$ & $89.25 \pm 0.18^{\mathrm{a}}$ \\
\hline LS72 & $90.62 \pm 0.46^{\mathrm{b}}$ & $88.74 \pm 0.27^{\mathrm{ab}}$ \\
\hline
\end{tabular}

Results are expressed as means \pm standard deviation $(n=3)$. Values in the same column with different superscript letter are significantly different $(p<0.05)$.

Time - kill kinetics curve: Time-kill kinetics profiles of the FFJs with L. plantarum and L. salivarius against Salmonella Typhi DMST 22842 at the MIC concentrations were evaluated. Both FFJs with $L$. plantarum and L. salivarius at $72 \mathrm{hrs}$ fermentation inhibited the Salmonella growth cycle curve of Salmonella Typhi, as shown in Figure 3. The results showed that treatment with FFJ did not have much affect on the number of Salmonella Typhi viable cells over the first 2, 4 and $6 \mathrm{hrs}$, which was approximately $7.2 \log$ CFU/mL. However, after that, the FFJs showed anti-Salmonella activity: pathogen cell viability gradually decreased from 6 to $18 \mathrm{hrs}$ with cell numbers of 4.0 and $3.0 \log$ CFU/mL for FFJs with $L$. plantarum and L. salivarius, respectively. The antiSalmonella effect of the FFJs against Salmonella viable cells was significantly different $(p<0.05)$ compared to the negative control, which was approximately $8.9 \log \mathrm{CFU} / \mathrm{mL}$. The reduction continued until $24 \mathrm{hrs}$, when all cells weredestroyed; this was also observedwhen treating with the antibiotic gentamycin. Salmonella treated with $1 x$ MIC of gentamicin showed rapid reduction in the number of viable cells, starting with $7.2 \log \mathrm{CFU} / \mathrm{mL}$ at $0 \mathrm{hrs}$ to $4.9 \log \mathrm{CFU} / \mathrm{mL}$ at $2 \mathrm{hrs}$, then gradually decreasing until all Salmonella cells were destroyed after 24 hrs of treatment. The time-kill kinetics allow anti-Salmonella agents to be classified as bactericidal and characterized the relationship between agent concentration and activity over time. These results illustrated the fast and sustained action of antiSalmonella agents presented in the FFJs. Time-kill kinetics show that the anti-Salmonella agents of FFJs produced by $L$. plantarum and $L$. salivarius should be administered at $2 \mathrm{hr}$ intervals following first contact with the pathogen. A study on purification and partial characterization of anti-Salmonella agents nameda novel bacteriocin, Paracin 1.7, which was synthesized by Lactobacillus paracasei HD1-7 and isolated from Chinese sauerkraut juice [27]. 


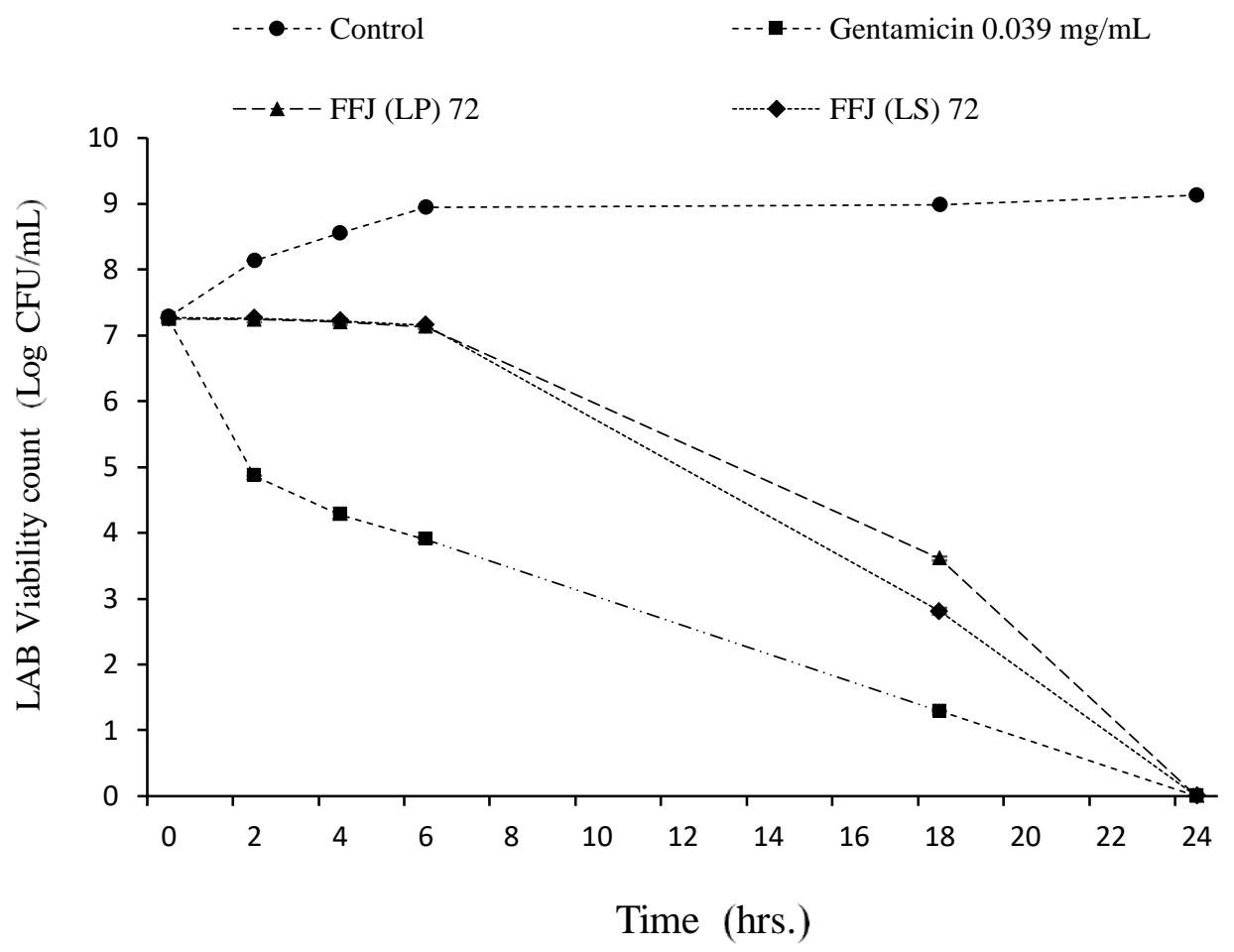

Figure 3. Time-kill kinetics curves of FFJs against Salmonella Typhi DMST 22842. The numbers of viable cells during treatment for 24 hrs was represented as the log reduction value of CFU counts of Salmonella. The error bars represent standard deviation of three replicates.

Antioxidative capacity: The changes of antioxidant capacities of mixed fruit juice and fermented fruitbased juice (FFJ) with $L$. salivarius (LS) and $L$. plantarum (LP) are presented in Figure 4. The results showed that antioxidant capacity measured by DPPH and FRAP in the FFJs were higher than those in mixed fruit juice. The DPPH radical scavenging activity and ferric reducing antioxidant power showed a significant increase from 0 to 72 hrs fermentation; 72 hrshad the highest antioxidant capacity. However, it then decreased after further fermenting to $96 \mathrm{hrs}$. This correlates to the viability and growth curve of $L$. salivarius and L. plantarum in fermented fruit-based juice during fermentation, which increased from 0 to $72 \mathrm{hrs}$, then decreased after 96 hrs. Antioxidant activities determined by DPPH exhibited a value of $2.27 \pm 0.03 \mathrm{mM} \mathrm{TE} / \mathrm{mL}$ in fermented fruit-based juice at $0 \mathrm{hrs}$. After $24 \mathrm{hrs}$ of fermentation by L. plantarum and L. salivarius, it rapidly increased to yield values of
$2.55 \pm 0.06$ and $2.62 \pm 0.05 \mathrm{mM} \mathrm{TE} / \mathrm{mL}$, respectively, which were significant $(p<0.05)$.Antioxidant activities showed little increase from 24 to $72 \mathrm{hrs}$, reaching $2.65 \pm 0.05$ and $2.64 \pm 0.04 \mathrm{mM} \mathrm{TE} / \mathrm{mL}$ for $L$. plantarum and L. salivarius, respectively. After $96 \mathrm{hrs}$ of fermentation, antioxidant activity significantly $(p<$ 0.05 ) lowered down to $2.08 \pm 0.06$ and $2.33 \pm 0.05$ $\mathrm{mM} T E / \mathrm{mL}$ for $L$. plantarum and L. salivarius, respectively. An increase in DPPH radical scavenging activity from 0 to72 hrs suggests that LAB fermentation produced active compounds to improve the availability of polyphenol compounds with proton-donating properties [28], which involved the electron transfer mechanism by DPPH [29]. In this study, the phenolic compounds were evaluated in the mixed fruit juice and the $72 \mathrm{hr}$ fermented fruit-based juice (FFJ). It was found that the phenolic compound significantly increased from $2.31 \pm 0.01 \mathrm{mg} \mathrm{GA} / \mathrm{mL}$ in the mixed fruit juice to $2.4 \pm 0.03 \mathrm{mg} \mathrm{GA} / \mathrm{mL}$ and 2.5 
$\pm 0.03 \mathrm{mg} \mathrm{GA} / \mathrm{mL}$ in the L. plantarum and L. salivarius fermentation, respectively. In the same way, LAB fermentation positively affected by the FRAP assay, as shown in Figure 3B. Antioxidant capacity rapidly increased from $0 \mathrm{hrs}$ with a value of $53 \pm 0.35 \mathrm{mM}$ $\mathrm{TE} / \mathrm{mL}$ to $66.46 \pm 0.26 \mathrm{mM} \mathrm{TE} / \mathrm{mL}$ and $68.34 \pm 0.80$ $\mathrm{mM} \mathrm{TE} / \mathrm{mL}$ for $L$. plantarum and $L$. salivarius, respectively, after 24 hrs of fermentation. From 24 to $72 \mathrm{hrs}$, there was a significant $(p<0.05)$ increase to $71.31 \pm 0.50 \mathrm{mM} \mathrm{TE} / \mathrm{mL}$ and $72.34 \pm 0.36 \mathrm{mM} \mathrm{TE} / \mathrm{mL}$ for L. plantarum and L. salivarius, respectively. After $96 \mathrm{hrs}$ fermentation, there was a significant decrease $(p<0.05)$ to $61.46 \pm 0.56 \mathrm{mM} \mathrm{TE} / \mathrm{mL}$ and $60.89 \pm 0.43$ $\mathrm{mM} T E / \mathrm{mL}$ for $L$. plantarum and $L$. salivarius, respectively. The results indicate that FRAP assay could measure the reducing potential of an antioxidant produced during fermentation by LAB. The changes on antioxidant activity of fermented fruit-based juice were attributed to the organic acid production during fermentation, which could eventually influence antioxidant activity by changing the content and structure of phenolic compounds. LAB fermentation shows beta-glucosidase activity, which could liberate phenolic compounds after acidic and enzymatic hydrolysis of polymerized phenolic compounds during fermentation [30]. In this study, the results have shown that fermented fruit-based juice by LAB for 24 and 72 hrs improved antioxidant activity. Similar findings have been found in other studies, such as with fermented mulberry juice [31], and indicates that FFJ has overall good potential for free radical scavenging and reducing power.
(A)

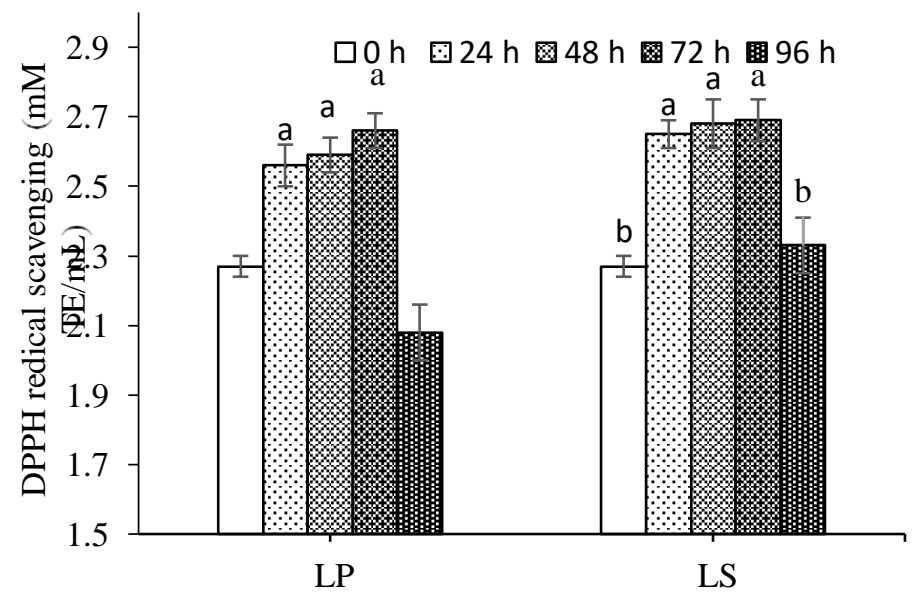

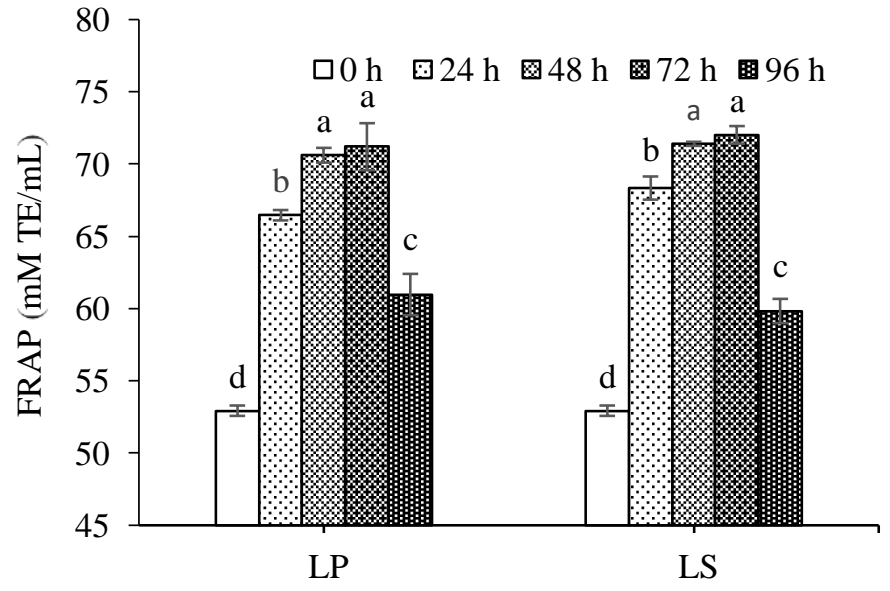

Figure 4. The antioxidant capacities of fermented fruit-based juice (FFJ) were detected and represented by (A) DPPH and (B) FRAP assay. Error bars indicate the standard deviations from two independent samples. Values in the same group column with different superscript letters are significantly different $(p<0.05)$ within a group.

Identification of volatile compounds: One of the most important characteristics of food products for consumer palatability is the flavor and aroma volatile compounds [32]. Fermentation is a biological approach to produce diverse aroma compounds and strong exotic flavors due to a wide array of extracellular enzymes, especially hydrolases, produced by microorganisms [33]. Table 3 shows volatile compounds of mixed fruit juice (MFJ) and fermented fruit-based juice (FFJ) by L. plantarum (LP) 
and L. salivarius (LS). 19 kinds of volatile compounds were identified in the MFJ and FFJ. The volatile profiles were identified by comparing mass spectra with the retention index database and characterized by the following classes: alcohols (7), aldehydes (2), acids (2), esters (5), ketones (1), phenol (1), and terpene (1). The most abundant volatile compounds in the FFJ were fruity aromas that have reported antimicrobial properties. Alcohols were the main dominant volatile compounds in FFJ. A major compound was isoamyl alcohol, which is a flavor aroma typically found in fruit such as pineapple [34], followed by an antimicrobial agent, benzene-ethanol [35]. Isobutyl alcohol, methionol, and benzyl alcohol were in less abundance. 1-Hexanol, a fruity flavor, and hotrienol, a fruity smelling compound, were dramatically increased in FFJ. Hexanol is derived from linoleic and linolenic acids through lipoxygenase pathway [36]. However, a 2,4Dimethylbenzaldehydet widely used for flavor and fragrance agents was less present in FFJ compared to MFJ. The production of organic acids, such as acetic acid, was higherin FFJ fermented by L. plantarum, which is facultatively hetero-fermentative and produces acetic acid and ethanol as main products [24]. In contrast, L. salivarius is homo-fermentative and efficiently synthesizes lactic acid [22]. The presence of lactic acid in the fermented fruit-based juice (FFJ) was determined by HPLC and was present in a higher quantity than in the non-fermented mixed fruit juice (data not shown). Esters have a significant contribution to the aroma of fruits. In this study, ethyl acetate, a volatile aroma compound in pineapple, was significantly decreased in FFJ. Ethyl acetate was reported to be a potential antimicrobial agent [37]. However, another fruity odor, ethyl L-(-)-lactate was formed and detected in FFJ but not in MFJ; this also occurred for ethyl nonanoate, methyl benzoate and ethyl3-hydroxy-hexanoate. The ketone, 3-hydroxy-2butanone, is typically used as a fruity flavor additive and was found in FFJ but not in MFJ. In addition, linalool, a monoterpene alcohol, is naturally found in many aromatic plants and known to exhibit various biological activities such as antimicrobial and antioxidant properties [38]. Interestingly, LAB fermentation significantly reduced 2,4-Bis(1,1dimethylethyl)-phenol, (2,4-DTBP) in FFJ. This organic compound is a common toxic secondary metabolite produced by various groups of organisms; however, it was reported that 2,4-DTBP exhibits in vitro and in vivo biological activities, such as antimicrobial and antioxidant activities [39]. Several flavor and aroma volatile organic compounds appeared after MFJ was fermented by Lactobacillus plantarum (LP) and Lactobacillus salivarius (LS). Consequently, the fermented fruited-based juice possessed a strong fruity flavor and aroma, in addition to effective antiSalmonella and antioxidant activity. This is similar to other fermented fruit juice research. For example, sweet lemon juice was fermented with Lactobacillus plantarum LS5 to produce a probiotic juice. The results showed the juice had antibacterial activity against S. Typhimurium and E. coli O157: H7. The fermented product also showed an increase of total phenolic compounds and antioxidant activity, as determined by DPPH radical scavenging and FRAP assay [40]. 
Table 3 Volatile compounds identified in mixed fruit juice (MFJ) and $72 \mathrm{hr}$ fermented fruit-based juice (FFJ) with $L$. plantarum (LP) and L. salivarius (LS).

\begin{tabular}{|c|c|c|c|c|}
\hline \multirow[t]{2}{*}{ Component RT } & \multirow[t]{2}{*}{ Compound Name } & \multicolumn{3}{|c|}{$\%$ relative peak area } \\
\hline & & MFJ & LP & LS \\
\hline & Alcohol & & & \\
\hline 6.6884 & Isobutyl alcohol & - & 6.0 & 4.7 \\
\hline 9.4810 & Isoamyl alcohol & - & 99.0 & 78.8 \\
\hline 13.2363 & 1-Hexanol & 2.5 & 18.9 & 21.3 \\
\hline 19.5323 & Hotrienol & 11.5 & 16.6 & 15.5 \\
\hline 21.9279 & Methionol & - & 1.1 & 0.5 \\
\hline 25.2658 & Benzyl alcohol & - & 0.7 & 0.7 \\
\hline \multirow[t]{2}{*}{25.9932} & Benzene-ethanol & - & 18.8 & 7.0 \\
\hline & Aldehyde & & & \\
\hline 2.5754 & Acetaldehyde & - & 0.4 & 0.5 \\
\hline \multirow[t]{2}{*}{24.1298} & 2,4-Dimethylbenzaldehyde & 5.1 & 3.3 & 3.6 \\
\hline & Acid & & & \\
\hline 15.7147 & Acetic acid & - & 9.5 & - \\
\hline \multirow[t]{2}{*}{24.6451} & Hexanoic acid & - & 0.8 & 0.5 \\
\hline & Ester & & & \\
\hline 3.4763 & Ethyl acetate & 72.0 & 42.8 & 30.0 \\
\hline 12.9393 & Ethyl L -(-)- lactate & - & 4.5 & 5.4 \\
\hline 17.8943 & Ethyl nonanoate & - & 2.0 & 1.2 \\
\hline 19.8459 & Methyl benzoate & - & 2.3 & 1.7 \\
\hline \multirow[t]{2}{*}{21.148} & Ethyl 3-hydroxyhexanoate & - & 0.6 & 0.7 \\
\hline & Ketone & & & \\
\hline \multirow[t]{2}{*}{11.463} & 3-hydroxy-2-butanone & - & 20.1 & 25.1 \\
\hline & Phenol & & & \\
\hline \multirow[t]{2}{*}{33.3645} & 2,4-Bis(1,1-dimethylethyl)phenol & 81.0 & 56.0 & 73.9 \\
\hline & Terpene & & & \\
\hline 18.0575 & Linalool & 13.5 & 14.3 & 15.5 \\
\hline
\end{tabular}

-, Not detectable.

${ }^{\mathrm{a}} \mathrm{RI}$ (retention index) based on VF-WASms capillary column using a series of C8-C20.

${ }^{b}$ All compounds were identified by comparison with mass spetra and retention index database.

c\% Relative peak area of volatile compounds is expressed as (compound peakarea/total compounds peakarea) $\times$ 100.

\section{CONCLUSION}

A novel functional fermented fruit-based juice (FFJ) made with pineapple (Ananas comosus L. Merr) and winter melon (Benincasa hispida Cogn) showed excellent growth capacity with $8 \log \mathrm{CFU} / \mathrm{mL}$ of probiotics, Lactobacillus plantarum and Lactobacillus salivarius. Study showed that the FFJ exhibited increased antioxidant capacity, as well as increased anti-Salmonella activity against Salmonella Typhi DMST 22842. These effects are due to the 
fermentation causing biotransformations of chemical substances in the fruit juice by $L A B$; this in turn formed bioactive compounds, which not only improved fruit flavor and aroma but also influenced anti-Salmonella and antioxidant activity._In addition to their high antioxidant and antipathogen activity, the FFJ had a reduced sugar content and is a suitable carrier for prebiotics and probiotics. Therefore, the FFJ can be served as a probiotic beverage and a functional fermented drink for vegan and non-diary consumption.

List of Abbreviations: FFJ: fermented fruit-based juice, LP: Lactobacillus plantarum, LS: Lactobacillus salivarius, MIC: minimum inhibitory concentration, MBC: minimum bactericidal concentration.

Completing Interests: There are no conflicts of interest to declare.

Authors' Contributions: Nualpun Sirinupong, Duangporn Kantachote and Chakree Thongraung designed the study, analyzed data and contributed fundamental conceptualization for the research; Wanida Laoseee performed research and drafted the manuscript; Nualpun Sirinupong and Worrapanit Chansuwan revised the manuscript. All authors read and approved the final version of the manuscript.

Acknowledgements and Funding: This work was funded by the National Research Council of Thailand (649/2563) and with scholarships from the Center of Excellence in Functional Foods and Gastronomy, Prince of Songkla University, Hat Yai, Songkhla 90112, Thailand. The authors are very grateful to Asst. Prof.
Dr. Narumol Thongwai from Chiang Mai University for Salmonella Typhi DMST 22842 donation.

\section{REFERENCES}

1. Sloan, AE: Favoring Fermented: Food Technology Magazine 2019, 73(11): 525.

2. Ranadheera CS, Vidanarachchi JK, Rocha RS, Cruz AG, Ajlouni S: Probiotic delivery through fermentation: dairy vs. non-dairy beverages. Fermentation 2017, 3(4):67. DOI: https://doi.org/10.3390/fermentation3040067

3. Prior RL: Fruits and vegetables in the prevention of cellular oxidative damage. Am J Clin Nutr 2003, 78:570S-578S. DOI: https://doi.org/10.1093/ajcn/78.3.570S

4. Naczk M, Shahidi F: Phenolics in cereals, fruits, and vegetables: Occurrence, extraction, and analysis. J Pharmaceut Biomed Ana 2006, 41(5):1523-1542. DOI: https://doi.org/10.1016/j.jpba.2006.04.002

5. Gardner PT, White TAC, McPhail DB, Duthie GG: The relative contributions of vitamin $\mathrm{C}$, carotenoids and phenolics to the antioxidant potential of fruit juices. Food Chem 2000, 68:471-474. DOI: https://doi.org/10.1016/S0308-8146(99)00225-3

6. Nayik GA, Nanda VA: Chemometric approach to evaluate the phenolic compounds, antioxidant activity and mineral content of different unifloral honey types from Kashmir, India. LWT- Food Sci Tech 2016, 74:504-513. DOI: https://doi.org/10.1016/j.lwt.2016.08.016

7. Sarkar D, Ankolekar C, Pinto M, Shetty K: Dietary functional benefits of Bartlett and Starkrimson pears for potential management of hyperglycemia: hypertension and ulcer bacteria Helicobacter pylori while supporting beneficial probiotic bacterial response. Food Res Int 2015, 69:80-90. DOI: https://doi.org/10.1016/j.foodres.2014.12.014

8. Mazlan FA, Annuar MS, Sharifuddin Y: Biotransformation of Momordica charantia fresh juice by Lactobacillus plantarum BET003 and its putative anti-diabetic potential. Peer J 2015, 3:1376. DOI: https://doi.org/10.7717/peerj.1376

9. Thomas $M K$, Murray R, Flockhart L, Pintar K, Fazil A, Nesbitt A, Marshall B, Tataryn J, Pollari F: Estimates of foodborne illness-related hospitalizations and deaths in Canada for 30 specified pathogens and unspecified agents. Foodborne Pathog Dis 2015, 12(10):820-827. DOI: https://doi.org/10.1089/fpd.2015.1966

10. Dougan G, Baker S: Salmonella enterica serovar Typhi and the pathogenesis of typhoid fever. Annu Rev Microbiol 
2014, 68:317-336. DOI: https://doi.org/10.1146/annurevmicro-091313-103739

11. Hiyoshi H, Tiffany CR, Bronner DN, Baumler AJ: Typhoidal Salmonella serovars: ecological opportunity and the evolution of a new pathovar. FEMS Microbiol Rev 2018, 42:527-541. DOI: https://doi.org/10.1093/femsre/fuy024

12. Ahirwar SK, Pratap CB, Patel SK, Shukla VK, Singh IG, Mishra OP, Kumar K, Singh TB, Nath G: Acid exposure induces multiplication of Salmonella enterica serovar Typhi. J Clin Microbiol 2014, 52(12):4330-4333. DOI: https://doi.org/10.1128/JCM.02275-14

13. Miller GL: Use of dinitrosalicylic acid reagent for determination of reducing sugar. Anal Chem 1959, 31:426. DOI: https://doi.org/10.1021/ac60147a030

14. Clinical and Laboratory Standards Institute. Methods for dilution antimicrobial susceptibility tests for bacteria that grow aerobically, approved standards (9th ed.). Wayne, PA: CLSI Document; 2012:M07-A9.

15. Foerster $\mathrm{S}$, Unemo $\mathrm{M}$, Hathaway $\amalg$, Low $\mathrm{N}$, Althaus $\mathrm{CL}$ : Time-kill curve analysis and pharmacodynamic modelling for in vitro evaluation of antimicrobials against Neisseria gonorrhoeae. BMC Microbiol 2016, 16:216. DOI: https://doi.org/10.1186/s12866-016-0838-9

16. Schillaci D, Arizza V, Dayton T, Camarda L, Di Stefano V: In vitro anti-biofilm activity of Boswellia spp. oleogum resin essential oils. Lett Appl Microbiol 2008, 47(5):433-438. DOI: https://doi.org/10.1111/j.1472-765X.2008.02469.x

17. Wu CC, Lin CT, Wu CY, Peng WS, Lee MJ, Tsai YC: Inhibitory effect of Lactobacillus salivarius on Streptococcus mutans biofilm formation. Mol Oral Microbiol 2015, 30:16-26. DOI: https://doi.org/10.1111/omi.12063

18. Jeong SY, Velmurugan $\mathrm{P}$, Lim JM, Oh BT, Jeong DY: Photobiological (LED light)-mediated fermentation of blueberry (Vaccinium corymbosum L) fruit with probiotic bacteria to yield bioactive compounds. LWT Food Sci Tech 2018, 93:158-166. DOI: https://doi.org/10.1016/j.lwt.2018.03.038

19. Adamenko K, Kawa-Rygielska J, Kucharska AZ, Głowacki A, Piórecki N: Changes in the antioxidative activity and the content of phenolics and iridoids during fermentation and Aging of Natural Fruit Meads. Biomolecules 2021, 11, 1113. DOI: https://doi.org/10.3390/biom11081113

20. Dall'Asta C, Cirlini M, Morini E, Galaverna G: Branddependent volatile fingerprinting of Italian wines from Valpolicella. J Chromatog A 2011, 218:7557-7565. DOI: https://doi.org/10.1016/j.chroma.2011.08.042

21. Mousavi ZE, Mousavi SM, Razavi SH, Hadinejad M, EmamDjomeh Z, Mirzapour M: Effect of fermentation of pomegranate juice by Lactobacillus plantarum and
Lactobacillus acidophilus on the antioxidant activity and metabolism of sugars, organic acids, and phenolic compounds. Food Biotechnol 2013, 27:1-13. DOI.: https://doi.org/10.1080/08905436.2012.724037

22. Rakin $M$, Vukasinovic $M$, Siler-Marinkovic $S$, Maksimovic M: Contribution of lactic acid fermentation to improved nutritive quality vegetable juices enriched with brewer's yeast autolysate. Food Chem 2007, 100:599-602. DOI: https://doi.org/10.1016/j.foodchem.2005.09.077

23. Li Z, Teng J, Lyu Y, Hu X, Zhao Y, Wang M: Enhanced antioxidant activity for apple juice fermented with lactobacillus plantarum ATCC14917. Molecules 2019, 24: 51. DOI: https://doi.org/10.3390/molecules24010051

24. Costa GM, Fonteles TV, De Jesus ALT, Rodrigues S: Sonicated pineapple juice as substrate for L. casei cultivation for probiotic beverage development: process optimization and product stability. Food Chem 2013, 139:261-266

DOI: https://doi.org/10.1016/j.foodchem.2013. 01.059

25. Reis JA, Paula AT, Casarotti SN, Penna AL: Lactic acid bacteria antimicrobial compounds: characteristics and applications. Food Eng Rev 2012, 4:124-140.

DOI: https://doi.org/10.1007/s12393-012-9051-2

26. Alakomi HL, Skyttä E, Saarela M, Mattila-Sandholm T, Latva-Kala K, Helander IM: Lactic acid permeabilizes gramnegative bacteria by disrupting the outer membrane. Appl Environ Microbiol. 2000, 66(5):2001-2005. DOI: https://doi.org/10.1128/aem.66.5.2001-2005.2000

27. Ge J, Sun $Y$, Xin $X$, Wang $Y$, Ping $W$ : Purification and partial characterization of a novel bacteriocin synthesized by Lactobacillus paracasei HD1-7 isolated from Chinese Sauerkraut juice. Scientific report 2016, 6:19366. DOI: https://doi.org/10.1038/srep19366

28. Santos AL, Freitas HV, Rodrigues S, Abreu VKG, de Oliveira Lemos T, Gomes WF, Narain N, Fernandes ALF: Production and stability of probiotic cocoa juice with sucralose as sugar substitute during refrigerated storage. LWT-Food Sci Tech 2019, 99:371-378. DOI: https://doi.org/10.1016/j.Iwt.2018.10.007

29. Kaprasob R, Kerdchoechuen O, Laohakunjit N, Sarkar D, Shetty K: Fermentation-based biotransformation of bioactive phenolics and volatile compounds from cashew apple juice by select lactic acid bacteria. Process Biochem 2017, 59:141-149. DOI: https://doi.org/10.1016/j.procbio.2017.05.019

30. Hur SJ, Lee SY, Kim YC, Choi I, Kim GB: Effect of fermentation on the antioxidant activity in plant-based foods. Food Chem 2014, 160:346-356. DOI: https://doi.org/10.1016/j.foodchem.2014.03.112 
31. Kwaw E, Ma Y, Tchabo W, Apaliya MT, Meng W, Sackey AS, Xiao L, Tahir Hrs E: Effect of Lactobacillus strains on phenolic profile, color attributes and antioxidant activities of lactic-acid-fermented mulberry juice. Food Chem. 2018, 250:148-154. DOI:

https://doi.org/10.1016/j.foodchem.2018.01.009

32. Kaprasob R, Kerdchoechuen O, Laohakunjit N, Sarkar D, Shetty K: Fermentation-based biotransformation of bioactive phenolics and volatile compounds from cashew apple juice by select lactic acid bacteria. Process Biochem. 2017, 59:141-149. DOI: https://doi.org/10.1016/j. procbio.2017.05.019

33. McFeeters RF: Fermentation microorganisms and flavor changes in fermented foods. J. Food Sci. 2004, 69:35-37.

DOI:

https://doi.org/10.1111/j.1365-2621.2004.tb17876.x

34. Holt1 S, Miks MHRS, Carvalho BT, Foulquie'-Moreno MR, Thevelein JM: The molecular biology of fruity and floral aromas in beer and other alcoholic beverages. FEMS Microbiol Rev 2019, 43:193-222. DOI: https://doi.org/10.1093/femsre/fuy041

35. Li B, Zhang D, Zhang Y, Shuang DJ, Lei LW, Wang HRS, Lin F. Synthesis and evaluation of novel benzene-ethanol bearing 1,2,4-triazole derivatives as potential antimicrobial agents. Med Chem Res 2016, 26:44-51. DOI: https://doi.org/10.1007/s00044-016-1724-6

36. Maldonado RR, da Costa Araújo L, da Silva Dariva LC, Rebac KN, de Souza Pinto IA, Prado JPR, Kamimura ES: Potential application of four types of tropical fruits in lactic fermentation. LWT-Food Sci Tech 2017, 86:254-260. DOI: https://doi.org/10.1016/j.lwt.2017.08.005

37. Lens C, Malet G, Cupferman S: Antimicrobial activity of Butyl acetate, Ethyl acetate and Isopropyl alcohol on undesirable microorganisms in cosmetic products. Int J Cosmet Sci 2016, 38(5):476-80. DOI: https://doi.org/10.1111/ics.12314

38. Kamatou GPP, Viljoen AM Linalool A: Linalool-Review of a Biologically Active Compound of Commercial Importance. NPC. Nat. Prod. Commun. 2008, 3(7): 1183-1192. DOI: https://doi.org/10.1177/1934578X0800300727

39. Zhao F, Wang P, Lucardi RD, Su Z, Li S: Natural Sources and Bioactivities of 2,4-Di-Tert-Butylphenol and Its Analogs. Toxins 2020, 12:35. DOI: https://doi.org/10.3390/toxins12010035

40. Hashemi SMB, Khaneghah AM, Barba FJ, Nemati Z, Shokofti SS, Alizadeh F: Fermented sweet lemon juice (Citrus limetta) using Lactobacillus plantarum LS5: Chemical composition, antioxidant and antibacterial activities. J. Funct. Foods 2017, 38: 409-414. DOI: https://doi.org/10.1016/j.jff.2017.09.040 